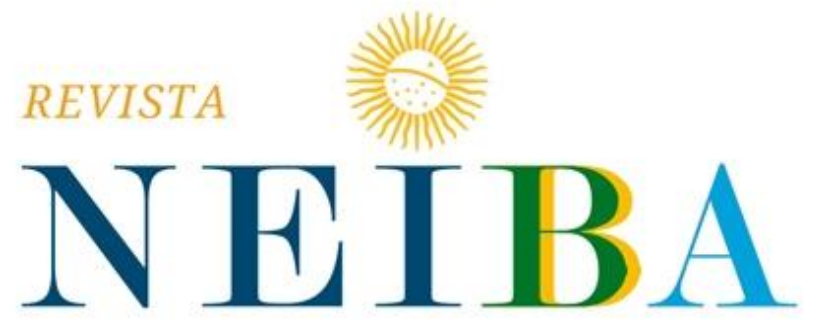

CADERNOS ARGENTINA-BRASIL
Volume 10, 2021, p. 01-23

DOI: 10.12957/neiba.2021.56130 | e56130 I ISSN: 2317-3459

\title{
'LOS ARGENTINOS SOMOS DERECHOS Y HUMANOS': A POLITICA EXTERNA DA DITADURA CIVIL-MILITAR ARGENTINA (1976-1983) DIANTE DA VISITA DA COMISSÃO INTERAMERICANA DE DIREITOS HUMANOS
}

'LOS ARGENTINOS SOMOS DERECHOS Y HUMANOS': ARGENTINE FOREIGN POLICY DURING THE CIVIL-MILITARY DICTATORSHIP (1976-1983) TOWARDS THE INTER-AMERICAN COMMISSION ON HUMAN RIGHTS' ON-SITE VISIT

\section{Gabriel Roberto Dauer ${ }^{1}$}

${ }^{1}$ Universidade Estadual Paulista (UNESP) - Programa de Pós-Graduação Interinstitucional em Relações Internacionais San Tiago Dantas (UNESP, UNICAMP, PUCSP), São Paulo, SP, Brasil. E-mail: gabrielrdauer@gmail.com ORCID: https://orcid.org/0000-0002-8998-4290

Recebido em: 19/11/2020 | Aceito em: 01/01/2021.

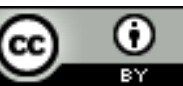

Esta obra está licenciada com uma Licença Creative Commons Atribuição 4.0 


\section{RESUMO}

As violações de direitos humanos na ditadura civil-militar argentina (1976-1983) foram tema de foros multilaterais, sendo um deles a Comissão Interamericana de Direitos Humanos $(\mathrm{CIDH})$ da Organização dos Estados Americanos. Nesse contexto, este trabalho analisa como a ditadura respondeu às críticas aos direitos humanos, particularmente quando da visita in loco da $\mathrm{CIDH}$ na Argentina em 1979 até a publicação de seu informe em 1980. Utilizamos da Análise de Política Externa para compreender as tomadas de decisão da ditadura para receber a $\mathrm{CIDH}$, os atores envolvidos e as consequências nacionais e internacionais desse evento. A visita transformou o campo de oportunidades de denúncia e visibilidade de opositores ao expor as atrocidades da ditadura. Contudo, as decisões do regime não foram lineares: os militares não eram os únicos interessados em defender seus interesses; grupos de direitos humanos, exilados e organizações internacionais disputaram esse campo, somadas desavenças internas na Junta Militar que dificultaram uma congruência diplomática.

Palavras-chave: Argentina; Ditadura; Comissão Interamericana de Direitos Humanos.

\section{ABSTRACT}

Human rights violations during the Argentine civil-military dictatorship (1976-1983) were a theme on multilateral forums, such as the Inter-American Commission on Human Rights (IACHR) of the Organization of American States (OAS). The article analyzes how the dictatorship reacted to criticisms regarding human rights violations in Argentina, especially during the IACHR's on-site visit in Argentina in 1979 until the publication of its report in 1980. Theoretically, Foreign Policy Analysis concepts were articulated to understand the decision-making of the dictatorship to receive the IACHR, the actors involved, and the national and international consequences of the event. IACHR's visit transformed the field of human rights actors' opportunities of complaints and the visibility of opponents by exposing the atrocities of the dictatorship, whose decisions were not linear: the military was not the only interested actor in defending its interests; human rights groups, exiles, and international organizations also disputed this 
narrative, while internal disputes in the Military Junta made Argentina's diplomatic congruence difficult.

Keywords: Argentina; Dictatorship; Inter-American Commission on Human Rights.

INTRODUÇÃO

O golpe civil-militar de 24 de março de 1976 na Argentina representou ao país e sua sociedade um dos períodos mais truculentos de sua história. Até a derrubada da ditadura em 1983, milhares de argentinos foram alvo de diversas graves violações de direitos humanos. Sob o mando da Junta Militar, mais de trinta mil pessoas desapareceram e cujos familiares e grupos de direitos humanos ainda buscam seu paradeiro (Calveiro, 2006; Novaro; Palermo, 2007). Intitulada pelos militares como "Processo de Reorganização Nacional", a ditadura argentina compartilhou e cooperou com seus países vizinhos do Cone Sul um esquema de extrema violência que causou inúmeras perdas materiais e humanas na região por meio da perseguição, prisão, demissão, exílios, tortura, desaparecimentos forçados e assassinatos no que se conhece atualmente por Operação ou Plano Condor (McSherry, 2005).

Na América Latina, grupos de direitos humanos, familiares de vítimas e exilados inseriram no debate global de direitos humanos as violências praticadas pelas ditaduras na região. Em contrapartida, em nome da defesa da nação, as ditaduras determinavam que, embora os direitos e liberdades estivessem garantidos constitucionalmente, essas prerrogativas poderiam ser revogadas sempre que houvesse ameaça à segurança nacional por conta de outros interesses do Estado ou em situações declaradas como crise (Roniger, 2018; Sikkink, 2018).

Dado esse cenário, o objetivo deste artigo é analisar como a ditadura respondeu às denúncias de violações aos direitos humanos, particularmente quando da visita in loco da Comissão Interamericana de Direitos Humanos (CIDH) da Organização dos Estados Americanos (OEA) em 1979 na Argentina até a publicação de seu informe em 1980. O evento foi um marco nas denúncias contra o regime, realizadas por opositores localizados no país e no exterior como grupos de direitos humanos, exilados, familiares 
de desaparecidos, membros de Organizações Não-Governamentais (ONGs) e de Organizações Internacionais (Ols), além de governos.

A metodologia empregada foi a análise documental das sessões da CIDH, com foco nas negociações da visita entre o órgão e a Junta Militar, complementada por artigos e livros sobre o evento. Teoricamente, usamos da Análise de Política Externa (APE) para compreender as tomadas de decisão da ditadura para receber a $\mathrm{CIDH}$, os atores envolvidos e as consequências nacionais e internacionais desse evento ${ }^{2}$.

A ditadura e seus opositores disputavam espaços de poder e discurso em relação aos direitos humanos. A visita marcou um ponto de inflexão na luta pela verdade e justiça no caso dos desaparecidos e outras violações de direitos humanos. Em resposta, a Junta Militar buscou realizar seus maiores esforços contra indivíduos e coletividades que demonstravam à $\mathrm{CIDH}$ as atrocidades da ditadura que assolavam a população na Argentina e em terras estrangeiras.

Criada em 1959, a CIDH ganhou maior proeminência na OEA ao realizar atividades de monitoramento, crítica às violações de direitos humanos e visitas in loco nos países (Baehr; Castermans-Holleman, 2004). Naquele período a agenda de direitos humanos não era primordial aos países; somado a isso, o mandato da CIDH dedicava-se à avaliação da conduta dos Estados em matéria de direitos humanos, o que limitava sua atuação na promoção desses direitos para ações de maneira educativa, sem autoridade ou procedimentos necessários de proteção (Engstrom, 2016; Roniger, 2018).

Na década de 1970, em resposta às violações de direitos humanos das ditaduras, a $\mathrm{CIDH}$ aumentou suas atividades no Cone Sul ${ }^{3}$. Se nos anos 1960 pouco atuou, nos anos 1970 realizou maiores investigações nos países comandados por militares:

\footnotetext{
${ }^{2}$ A APE analisa decisões tomadas por atores estatais e não estatais, em cargos de autoridade ou não, sob diversos níveis (Hill, 2003; Hudson, 2014). Essas ações (inscritas em dimensões estruturais) moldam a política externa de um país, ilustram a intencionalidade e a predisposição dos atores (Carlsnaes, 2013) e integram distintas etapas da APE: processo de tomada de decisão; formulação de agendas; implementação; e avalição da política externa (Salomón; Pinheiro, 2013). Portanto, para atingir seus objetivos, os atores mobilizam recursos direcionados a conciliar exigências e necessidades domésticas e internacionais (Brighi; Hill, 2008; Mintz; DeRouen, 2010).

${ }^{3}$ Na opinião de Engstrom (2016), uma posição mais ativa da CIDH deveu-se às mudanças políticas domésticas nos Estados Unidos da América (EUA) ao ter proporcionado mais espaço de atuação a grupos de direitos humanos. Essa abertura ocorreu no governo de Jimmy Carter (1977-1981), cujo mandato buscou institucionalizar a agenda de direitos humanos na política externa estadunidense (Schimidli, 2013). Ademais, conforme o site oficial da CIDH, até fevereiro de 2020 foram realizadas 102 visitas: https://www.oas.org/en/iachr/activities/countries all.asp.
} 
[...] não era investigar casos isolados de violações, mas documentar e reportar episódios de graves e sistemáticas violações para exercer pressão na melhoria geral do panorama de direitos humanos do país em questão. [...] a principal contribuição da Comissão era realizar um impacto indireto na elaboração de normas, em particular no que se refere à rejeição da doutrina de segurança nacional (Engstrom, 2016, p. 218, tradução nossa).

Após breve contextualização, apresenta-se a seguir a estrutura do artigo, estruturado em duas seções, ademais desta introdução e conclusão: na primeira, discorre-se sobre o processo de negociação entre a $\mathrm{CIDH}$ e a ditadura para a visita na Argentina. Na segunda parte, analisa-se como a política externa da ditadura respondeu à visita da $\mathrm{CIDH}$ e ao seu relatório, além de pressões domésticas e internacionais que fracassaram o esforço dos militares em impedir a visibilidade das denúncias relativas às suas atrocidades.

\section{O HORROR SOB HOLOFOTES INTERNACIONAIS: A VISITA DA CIDH NA ARGENTINA} (1979)

Na década de 1970, assuntos que antes eram considerados restritos ao âmbito doméstico estatal passaram a ser tema de escrutínio da opinião pública internacional, como o caso de graves violações de direitos humanos. Na Argentina, os militares reavaliaram suas ações de vigilância e atrocidades como o desaparecimento forçado por conta das duras críticas da comunidade internacional às práticas repressivas na ditadura chilena de Augusto Pinochet (Roniger, 2018; Sikkink, 1993).

O isolamento internacional do Chile serviu de exemplo à Junta Militar, que aplicou uma política sistemática de desinformação e negação das graves violações de direitos humanos na Argentina: alegava que os desaparecidos não existiam e eram uma mentira difundida por redes de conspiração atreladas ao comunismo internacional (Lloret, 2016; Roniger, 2018). Ao mesmo tempo das denúncias contra a ditadura, a Junta Militar rebatia as críticas ao salientar ser autêntica defensora dos direitos humanos.

Não menos relevante, cabe sublinhar que não existia plena concordância entre as organizações, grupos de direitos humanos, familiares de presos políticos e exilados no modo pelo qual a denúncia contra os militares deveria ser feita. Em uma conjuntura em que a defesa dos direitos humanos ganhava espaço transnacional (seja em foros ou organizações multilaterais, em movimentos sociais, na mídia e na política internacional), 
muitos desses atores consideravam que era estratégico adotar o discurso dos direitos humanos como uma forma de sensibilizar a opinião pública internacional sobre as atrocidades na Argentina (Roniger, 2018).

Entretanto, o discurso dos direitos humanos não foi adotado sem críticas. Grupos guerrilheiros (Montoneros, Partido Revolucionário dos Trabalhadores, Exército Revolucionário do Povo - PRT-ERP) e exilados argentinos (dos quais alguns também eram membros das guerrilhas) defendiam a luta armada para derrubar a ditadura ao invés de se valer de alianças, acordos e cooperações com "burgueses e protoburgueses" (Jensen, 2010, p. 14, tradução nossa) em nome de direitos humanos fundados em preceitos capitalistas e liberais (Roniger, 2018). A nível macro, as desavenças internas entre os argentinos na luta contra o regime eram anteriores à ditadura: "[...] as identidades políticas prévias nunca se diluíram [...] cada diferença programática, tática, de interpretação do passado ou de avaliação das futuras ações não poucas vezes tornaram-se irreconciliáveis" (Jensen, 2010, p. 38, tradução nossa). Os usos dos direitos humanos como instrumento das denúncias pode ser visto ora como uma nova forma de convivência política, ora como uma mudança tática ou um oportunismo político de ex-militantes armados a fim de não transparecer as diferenças e disputas internas dos grupos (Jensen, 2010).

A visita da $\mathrm{CIDH}$ (6 a 20 de setembro de 1979) marcou um ponto de inflexão na ditadura: a comunidade internacional soube dos casos de desaparecimento forçado, das torturas e das prisões arbitrárias. Não havia como simplesmente apagar o passado ou deter a publicidade que as graves violações de direitos humanos na Argentina haviam alcançado mundialmente (Jensen, 2010; Novaro; Avenburg, 2009).

Mas para que a $\mathrm{CIDH}$ pudesse de fato realizar a visita, houve um longo e burocrático processo de negociação com a Junta Militar. Antes de estar de acordo, os militares oferecem à CIDH proporcionar informações sobre a Argentina, opção descartada pelos membros da Comissão (Jensen, 2010; Novaro; Avenburg, 2009). Quando a Argentina aceitou a visita, a primeira tentativa da ditadura foi limitar as 
atividades da CIDH ao estudo da legislação do país, proposta também recusada já que o órgão conhecia minimamente seus aparatos repressores (Novaro; Avenburg, 2009) ${ }^{4}$.

O convite formal da ditadura chegou à CIDH em 18 de novembro de 1978. A data prevista da visita era para maio de 1979, contudo uma reestruturação e mudança de autoridades na $\mathrm{CIDH}$ fizeram com que a visita fosse adiada para setembro de 1979 (Jensen, 2010). Com a postergação da visita, a Junta Militar conseguiu preparar-se para receber a $\mathrm{CIDH}$ no sentido de aumentar as prisões, as perseguições, os sequestros e os desaparecimentos forçados de militantes de organizações de direitos humanos que trabalhavam para coletar informações e denúncias contra a ditadura (Novaro; Palermo, $2007)^{5}$.

Os militares demonstravam grande preocupação em relação à visibilidade dos familiares das vítimas que trabalhavam para divulgar na imprensa nacional e internacional a visita da $\mathrm{CIDH}$, visto que determinados setores da população argentina não estavam incondicionalmente a favor do regime e poderiam ser facilmente atraídos, além de outros fatores como a crise econômica que se acentuava. Na perspectiva dos militares, para neutralizar as ações dos familiares e dos grupos de direitos humanos, era fundamental aumentar a intimidação e o desaparecimento desses atores, como as ameaças realizadas na Praça de Maio contra as Mães da Praça de Maio e seus apoiadores (Jensen, 2010).

No controle dos meios nacionais de comunicação, os militares buscaram deter a visibilidade das denúncias e obter apoio ao governo. O objetivo também era direcionar seu discurso nacionalista contra a visita da Comissão:

A resposta cidadã contra a visita foi manipulada pelo governo de diversos modos. Um deles foi a publicação de expressões de políticos, empresários, colégios profissionais ou jornalistas que manifestavam seu agradecimento às

\footnotetext{
${ }^{4}$ Os comissionados da CIDH exigiam não apenas abertura para consultar as autoridades argentinas, mas que tivessem acesso a todos os documentos disponíveis, garantia de se deslocar livremente pelo país para visitar prisões e falar com nacionais (Lisińska, 2019).

${ }^{5} \mathrm{Na} 43$ a sessão da CIDH foi decidido que a Comissão prepararia um relatório sobre a situação dos direitos humanos na Argentina. Conforme a CIDH, caso a Argentina não a convidasse para realizar a visita, a própria faria a solicitação ao país (IACHR, 1978a). Na 44a sessão, a Argentina convidou a CIDH para visitar o país por meio de seu Ministro de Relações Exteriores, que participou da sessão junto de outros oficiais do ministério. O convite, contudo, restringia-se à análise das condições jurídicas e legais da Argentina. Essa restrição fez com que a CIDH solicitasse à Argentina as especificações das atividades que a $\mathrm{CIDH}$ poderia realizar no país. O propósito era conhecer se a CIDH possuiria as condições necessárias para que pudesse exercer seu mandato da forma mais completa possível (IACHR, 1978b). Na 45a sessão a CIDH aceitou realizar a visita após a ditadura ter acatado suas exigências (IACHR, 1978c).
} 
Forças Armadas por terem devolvido à Argentina a desejada paz (Jensen, 2010, p. 101, tradução nossa).

A vitória do time argentino no Campeonato Juvenil no Japão e a distribuição de adesivos com os dizeres "Os argentinos somos direitos e humanos" (Jensen, 2010, p. 102, tradução nossa) se somaram às estratégias militares:

Essa campanha publicitária foi aprovada por um decreto secreto assinado por
Albano Harguindeguy, que contou com financiamento estatal e foi realizada
pela empresa publicitária Burson-Masteller, que já havia colaborado com os
militares durante a Copa do Mundo de 1978. O objetivo da campanha
publicitária era que cada automóvel de cada cidadão mostrasse aos
'inspetores' quem eram os argentinos e qual era sua opinião sobre os direitos
humanos (Jensen, 2010, p. 102-103, tradução nossa).

A própria visita da CIDH foi utilizada pela ditadura como uma estratégia de duplo objetivo: minimizar as críticas internacionais aos direitos humanos e recuperar a transferência de fundos financeiros dos EUA, bloqueados exatamente pelas denúncias de violações de direitos humanos (Novaro; Avenburg, 2009). Logo, era necessário melhorar a imagem internacional da Argentina, ainda mais pelo montante de suprimentos militares e econômicos provenientes dos EUA e da Europa (Sikkink, 1993).

O que os militares não esperavam era que a visita materializou na esfera internacional as ações de denúncia contra a ditadura na imprensa internacional e em foros multilaterais (Jensen, 2010). A presença dos funcionários da CIDH na Argentina reforçou na sociedade o debate sobre os direitos humanos nas ruas, praças, universidades, cafés, bares e delegacias se falava sobre os desaparecidos, as torturas e os exilados. Era inevitável prestar atenção ao aglomerado de familiares e grupos de direitos humanos reunidos em imensas filas para prestar seus depoimentos à CIDH (D’Antonio, 2017; Jensen, 2010), como se observa na Figura 1 abaixo: 
Figura 1 - Na sede da OEA em Buenos Aires, pessoas esperavam para prestar seus depoimentos à $\mathrm{CIDH}$

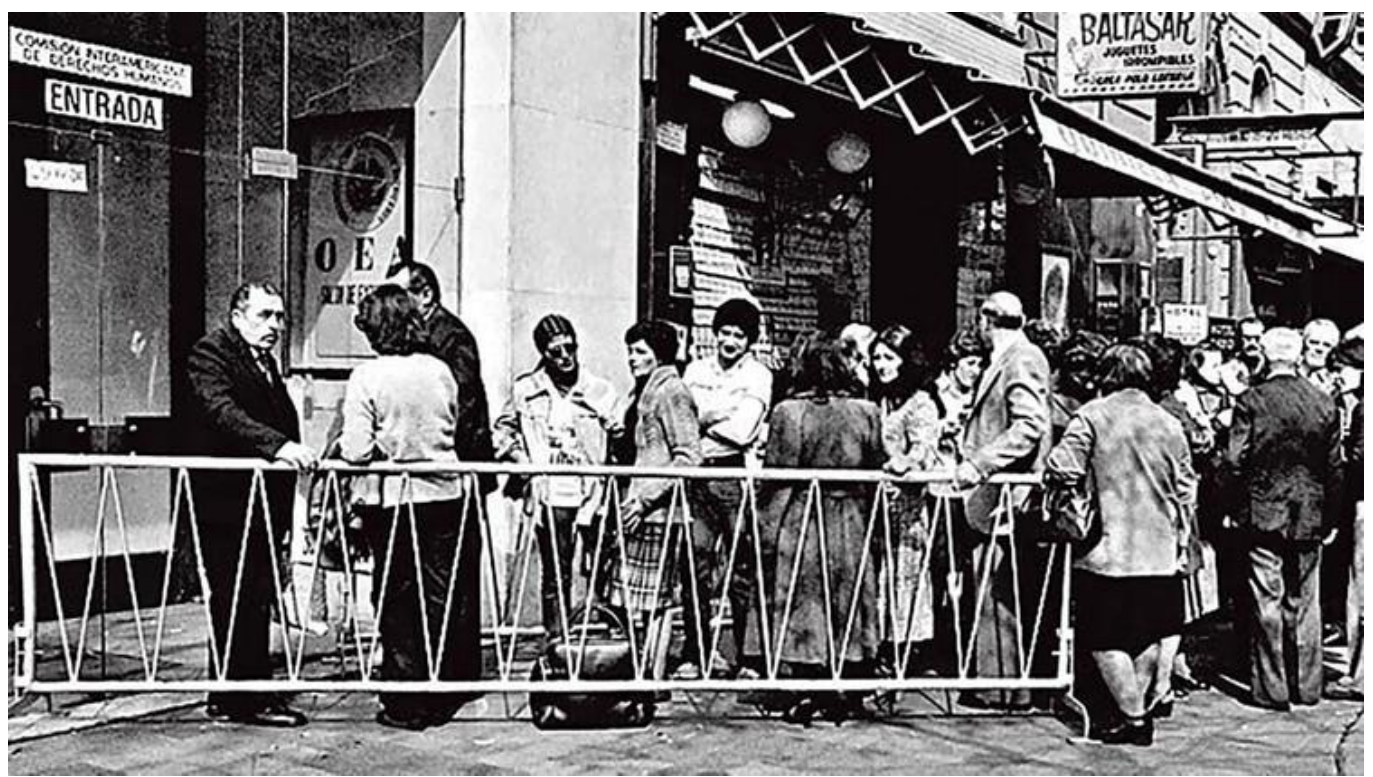

Fonte: Comisión Provincial por la Memoria (CPM) (2020).

Existiam atritos entre a CIDH e a Assembleia Geral da OEA. Nos anos 1970 e 1980, a $\mathrm{CIDH}$ era vista com muita desconfiança pelas ditaduras (Jensen, 2010; Novaro; Avenburg, 2009). Na Assembleia Geral, governos autoritários votavam em bloco contra resoluções que tratavam do quadro de direitos humanos desses países, boicotando as atividades da CIDH (Novaro; Avenburg, 2009). Logo, embora os informes da Comissão fossem relevantes para tornar público os casos de violações de direitos humanos e realizar uma condenação internacional dos governos envolvidos, esses documentos não eram garantia de que o país seria sancionado pela OEA.

No caso da Argentina, o relatório da CIDH foi enviado à Junta Militar em fevereiro de 1980 e publicado em versão final em 18 de abril de 1980, dadas as reconsiderações e críticas enviadas pela Argentina (D’antonio, 2017; Novaro; Avenburg, 2009) ${ }^{6}$. Ficou patente que as más explicações oficiais da ditadura sobre as mortes, torturas, detenções e desaparecimentos "[...] não eram parte das consequências não desejadas

\footnotetext{
${ }^{6} \mathrm{O}$ relatório foi aprovado na 48 a sessão da $\mathrm{CIDH}$ e posteriormente enviado ao governo da Argentina para que o mesmo pudesse expor suas colocações (IACHR, 1979b). O informe não foi publicado na Argentina durante a ditadura. Somente em 1984, com o título "O informe proibido" que os argentinos tiveram acesso ao documento. Soma-se a esse fato o Prêmio Nobel concedido a Adolfo Pérez Esquivel (renomado integrante do movimento de direitos humanos na Argentina). Esses dois acontecimentos em 1980 foram responsáveis por criar na sociedade argentina um senso de legitimidade para com a pauta dos movimentos de direitos humanos, suas propostas e objetivos (Quiroga, 2004).
} 
de uma 'dura e sangrenta batalha', nem constituíam fatos isolados ou excessos individuais, nem se tratava de invenções fabricadas pelos 'subversivos' ou de seus 'companheiros de viagem' ocasionais" (Jensen, 2010, p. 155, tradução nossa).

O informe não foi discutido na Assembleia Geral da OEA em novembro de 1980, o que representou certa vitória dos militares pela não condenação da Argentina (D’Antonio, 2017; Engstrom, 2016). Contudo, apesar da Argentina ter ficado livre de condenações, a visita da CIDH teria marcado um "[...] momento decisivo no desenvolvimento de sua identidade como uma instituição independente e operacional de direitos humanos" (Engstrom, 2016, p. 220, tradução nossa). A relevância da visita foi simbólica e política devido aos esforços da $\mathrm{CIDH}$ em ter posicionado a ditadura nos holofotes do escrutínio internacional e ter exposto a maior prática de violência da ditadura: os desaparecimentos (Jensen, 2010). Outrossim, o documento final da CIDH destacou internacionalmente os esforços da oposição contra a ditadura (Quiroga, 2004) desde a Copa do Mundo de 1978 e até durante a dita "guerra anticolonial" (Jensen, 2010, p. 12) da Guerra das Malvinas em 1982, quando a ditadura estava prestes a ruir.

A visita aproximou a agenda global de direitos humanos com o contexto local da Argentina e, principalmente, de sua população. O esforço dos comissionados, grupos de direitos humanos e exilados foi relevante ao expor as violências da Argentina às normas internacionais de direitos humanos. Portanto, melhor do que ter explicado o significado desses direitos humanos no quadro "educativo" de seu mandato aos Estados, a CIDH foi capaz de debatê-los e criticá-los publicamente com os argentinos e a comunidade internacional. Ao longo do tempo, a visita foi importante pois auxiliou na construção, aplicação e reconstrução dos direitos humanos na Argentina e de outros países e sociedades da região ${ }^{7}$.

\footnotetext{
${ }^{7}$ Após a visita, a situação dos direitos humanos na Argentina foi pauta de outras sessões da Comissão e da Assembleia Geral da OEA: 52a sessão de 1980 sobre denúncias de prisões arbitrárias de membros de grupos de direitos humanos (IACHR, 1980); 10a sessão regular da Assembleia Geral da OEA, que tratou sobre o desaparecimento de pessoas após serem detidas e ameaças contra instituições de direitos humanos (IACHR, 1981); 55a sessão de 1982 sobre casos individuais de argentinos que haviam denunciado terem sofrido violações de direitos humanos (IACHR, 1982a); 56a sessão de 1982 sobre denúncias gerais de violações de direitos humanos na Argentina como presos à disposição do Poder Executivo Nacional, desaparecimentos, Estado de Sítio e novas detenções arbitrárias (IACHR, 1982b); 20ạ sessão regular da Assembleia Geral da OEA, que discorreu sobre denúncias de pessoas que haviam sido presas e depois tinham desaparecido, direitos políticos, Estado de Sítio e casos individuais (IACHR, 1982C).
} 


\section{DIPLOMACIA DEFENSIVA E NACIONALISTA: REAÇÕES DA DITADURA À VISITA DA CIDH}

Na disputa de narrativas sobre o panorama dos direitos humanos na Argentina, estiveram envolvidos diversos atores estatais e não estatais: militares, diplomatas, grupos de direitos humanos, exilados e outros atores mobilizados local e transnacionalmente. Para compreender como a política externa da ditadura respondia às denúncias de graves violações de direitos humanos na Argentina, utilizam-se conceitos da Análise de Política Externa (APE).

Num primeiro momento, o aumento das denúncias internacionais entre 1976 e 1979 fez com que a Junta Militar modificasse seu discurso. Houve uma distensão da posição dos militares, ou seja, admitiam que existiram violações de direitos humanos, mas que resultavam de uma suposta crise no país causada por atividades subversivas de argentinos terroristas em escala nacional e internacional contra seu próprio povo (Novaro; Palermo, 2007).

A Junta Militar declarava-se como defensora dos direitos humanos e que, para tanto, foi necessário combater quem considerava de verdadeiros algozes: terroristas ou subversivos que violavam os direitos humanos ao ameaçarem a vida, a liberdade e a integridade dos argentinos (Novaro; Avenburg, 2009). Para os militares, as denúncias contra a Argentina não eram legítimas porque era preciso uma compreensão mais abrangente da história do país antes que fosse acusado de violar os direitos humanos de seu povo (Jensen, 2010).

Com o objetivo de minimizar as críticas, a Junta Militar participou de reuniões em distintos foros multilaterais e visitou países envolvidos nas denúncias:

\footnotetext{
[...] em 1977, Videla tinha viajado a Washington, onde foi recebido pela imprensa progressista e por funcionários da administração de Carter. [...] No caso das Nações Unidas, a Junta Militar deu ordens precisas ao seu embaixador em Genebra para que buscasse modificar as votações dos países membros, evitando que a Argentina sofresse condenações como aquelas pelas que passaram os regimes do Apartheid na África do Sul e de Pinochet no Chile. [...] As relações entre a Junta Militar e as Nações Unidas foram tortuosas. Se em ocasiões a diplomacia argentina conseguiu que o país ficasse de fora da lista dos países envolvidos com violações aos direitos humanos, em outras não pôde frear as condenações (Jensen, 2010, p. 92, tradução nossa, grifo nosso).
}

As controvérsias entre e dentro de familiares de desaparecidos, exilados e grupos guerrilheiros na denúncia contra a ditadura existiam também entre os militares para 
defender o regime das acusações. Além das atividades de neutralização ou diminuição das críticas internacionais, estavam as desavenças dentro das próprias Forças Armadas (Novaro; Avenburg, 2009; Quiroga, 2004). As distintas formas responder à subversão na chamada guerra revolucionária eram mais notórias particularmente entre a Marinha e o Exército (Novaro; Palermo, 2007), cujos embates dificultavam a execução de políticas e a articulação entre os militares, também presente na formulação e implementação da política externa da ditadura (Lisińska, 2019) ${ }^{8}$.

Ao aceitar a visita da CIDH, os militares consentiram com o discurso de direitos humanos. Os militares da ala moderada buscavam com a visita "limpar" a imagem da ditadura e barrar as atividades de resistência e denúncia dos movimentos e grupos de direitos humanos na Argentina e fora do país (Novaro; Palermo, 2007). Em oposição, os militares da linha-dura não estavam até o momento preocupados com as denúncias por não considerarem ser um problema grave ao regime. Ao contrário dos moderados, os militares da linha-dura defendiam a repressão até a necessária morte dos dissidentes e que "[...] tinha tão pouco sentido dar ouvidos às pressões internacionais como levar a sério formalidades jurídicas que havia se decidido respeitar só na aparência" (Novaro; Palermo, 2007, p. 374). Para a linha-dura, o isolamento internacional da Argentina era opção viável para "aprofundar" o estágio do Processo de Reorganização Nacional.

Nesse sentido, no âmbito nacional, houve um descontentamento do lado mais radical das Forças Armadas, ao mesmo tempo que eram satisfeitos os interesses do setor mais brando da ditadura que buscavam melhorar a imagem internacional da Argentina e de suas relações bilaterais, especialmente com os EUA. Para a linha-dura, o aceite da visita da CIDH pela Junta Militar representava à Argentina o respaldo às pressões internacionais, promovidas pela subversão (Novaro; Palermo, 2007). Por outro lado, no nível internacional, a Junta Militar satisfez aos próprios interesses da CIDH ao ter prestado informações sobre os direitos humanos e ter realizado pequenas mudanças que mesmo paliativas, acabaram por impedir a condenação do país.

\footnotetext{
${ }^{8}$ Em termos gerais, tem-se duas linhas de condução do projeto golpista, a linha dura e a linha moderada. Para a linha dura, a intervenção deveria ocorrer sem quaisquer ingerências de partidos políticos e sindicatos no governo, sem estipular um período ou data para a volta da democracia. Para os moderados, o chamado Processo de Reorganização era um momento de transição (entre três e cinco anos) para o restabelecimento de um governo democrático, cuja participação militar ainda estaria presente (Quiroga, 2004).
} 
A materialização das ações da ditadura em relação à visita da CIDH faz parte da etapa de implementação da política externa estatal, momento crucial para pôr em prática os objetivos e as decisões do Estado em contraposição aos interesses de outros Estados e demais atores no sistema internacional. Para compreender as ações de implementação da política externa argentina na ditadura, recorre-se ao estudo de Brighi e Hill (2008). Segundo os autores, fatores domésticos são componentes essenciais da implementação da política externa quando são avaliadas as necessidades e os objetivos nacionais com a projeção internacional do país. A implementação não se trata tão somente de alcançar os objetivos de política externa por meios eficazes, mas da habilidade dos governos em "[...] extrair e mobilizar recursos de seu público, seja na forma material ou não, e canalizar esses recursos na busca dos objetivos estabelecidos" (Brighi; Hill, 2008, p. 125, tradução nossa). No caso da Argentina, a falta de consenso entre os militares dificultava o processo de implementação de suas ações na política externa, o que desgastava a própria ditadura.

A visita da $\mathrm{CIDH}$ e as denúncias demonstram que a implementação da política externa dependia também da ação de outros atores, estatais ou não estatais, em contextos domésticos ou internacionais. No caso dos militares, o objetivo era adquirir uma boa imagem internacional da Junta Militar e demonstrar ao mundo que a Argentina era autêntica defensora dos direitos humanos. Para tanto, uma das estratégias de implementação da política externa da ditadura foi desqualificar as denúncias em três níveis de ação: i) identificar os responsáveis por realizarem as denúncias contra o país; ii) refutar o conteúdo das denúncias e difundir uma compreensão distinta do que ocorria na Argentina; e iii) qualificar todas as ações dos denunciantes como uma campanha anti-Argentina (Franco, 2008; Jensen, 2010).

Além disso, os militares questionavam as denúncias e as críticas como as da CIDH enquanto ingerência externa e desrespeito à soberania nacional do país. Os denunciantes afirmavam que a proteção dos direitos humanos não estava limitada ao respeito de princípios de política internacional, como os de não intervenção e de autodeterminação dos povos, e acusavam os militares de utilizarem esses princípios 
como estratégia de se eximirem das responsabilidades perante as suas atrocidades (Novaro; Avenburg, 2009; Jensen, 2010).

No caso dos usos políticos da soberania estatal, Sikkink (1993) traz uma reflexão conceitual e como sua natureza pode se transformar a partir de políticas e práticas de direitos humanos de atores não estatais transnacionais. Para a autora, o que se compreende e se espera da soberania estatal são elementos constantemente reforçados por ações dos Estados e de atores não estatais. O caso da Argentina evidencia como a soberania estatal foi reinterpretada e projetada de distintos ângulos ao longo da ditadura. As denúncias e as visitas de Ols e ONGs demonstram como o trabalho desses atores e instituições podem dar maior visibilidade às práticas repressivas dos Estados (Sikkink, 1993). Essas pressões podem criar canais que façam com que os Estados respondam às acusações e modifiquem seu relacionamento com outros atores e governos, como quando a Junta Militar aceitou a visita da CIDH.

Ou seja, a soberania é moldada conforme temáticas prioritárias da política internacional e que podem limitar a atuação do Estado (Sikkink, 1993). Na década de 1970, houve um aumento de atores voltados à defesa dos direitos humanos e a Argentina fez parte desse processo, não apenas de maneira passiva ao receber críticas ou visitas de órgãos externos como a $\mathrm{CIDH}$, mas que domesticamente viu o surgimento de organizações e grupos de direitos humanos atuantes nessa esfera internacional. As atividades desses atores na Argentina e no exterior tornaram-se mais intensas quando da visita da $\mathrm{CIDH}$ pela possibilidade de potencializar a disseminação de informações sobre as atividades repressivas praticadas pela ditadura.

De acordo com Míguez e Morgenfeld (2017), a visita da CIDH gerou uma comoção e reação popular que modificaram as decisões de política externa dos militares. A resposta da sociedade argentina constituiu um importante fator doméstico às decisões e implementações diplomáticas da Junta Militar ao ter exposto um problema interno (os desaparecimentos, as prisões arbitrárias e os assassinatos) que se conectava ao discurso mais geral de direitos humanos da década de 1970 (Míguez; Morgenfeld, 2017). Na mesma linha, Mintz e DeRouen Jr. (2010) destacam que as pressões políticas nacionais geralmente estão conectadas com as pressões internacionais quando se trata 
de fatores domésticos na tomada de decisão da política externa. Na Argentina, houve uma simultaneidade de ações domésticas e internacionais: as denúncias do exterior (de instituições internacionais, de exilados) e de grupos de direitos humanos na Argentina se complementavam no sentido de somarem esforços em diferentes escalas geográficas.

O modelo estratégico-relacional de Brighi e Hill (2008) auxilia na visualização de como e por que os militares modificaram a implementação de sua política externa contra as denúncias devido à visita da $\mathrm{CIDH}^{9}$. Muitas vezes, o contexto acarreta em restrições, altera preferências e provoca atritos ou boas relações entre os atores. Contudo, nem o contexto nem a estratégia são suficientes para explicar o sucesso ou o fracasso de determinada política externa em atingir determinado resultado. É na constante interação entre atores e contexto que o comportamento dos atores responsáveis pela implementação da política externa se expressa de fato. Na visita da $\mathrm{CIDH}$, essa interação ocorreu quando os comissionados e a população argentina se aproximaram e trocaram informações, o que dificultou à Junta Militar concretizar seus esforços de melhorar a imagem e o reconhecimento internacional da Argentina como país defensor dos direitos humanos.

Pode-se também observar efeitos materiais do discurso da ditadura sobre direitos humanos nas relações Argentina-EUA. A Junta Militar esperava que com a visita da CIDH os EUA retirariam as suas sanções econômicas e militares ao país ${ }^{10}$. Uma ação simbólica - representada por um importante organismo internacional voltado ao monitoramento de direitos humanos - foi tomada como instrumento de política exterior para alcançar objetivos materiais. Esses fatores simbólicos, discursivos e materiais nas camadas hierárquicas do sistema internacional não são estáticos: "[...] a distinção tradicional entre 'high politics' e 'low politics' reivindicada pela primazia de questões políticas e militares é cada vez mais problemática num mundo em que temas como cultura

\footnotetext{
${ }^{9}$ O elemento estratégico trata-se dos objetivos dos atores e o relacional de que a compreensão dos atores e de seus comportamentos só é inteligível quando analisados em seu contexto (Brighi; Hill, 2008).

${ }^{10}$ Os EUA visitaram a Argentina em 1977. Dentre as pessoas responsáveis por colocar em prática a política externa de direitos humanos do governo de Jimmy Carter foi Patricia Derian, Coordenadora do Departamento de Estado para Direitos Humanos e Assuntos Humanitários. Após a visita de Derian em 1977, os EUA bloquearam sua assistência econômico-militar à ditadura (Schmidli, 2013).
} 
tornaram-se (ou melhor, voltaram a ser) objeto de grande contestação" (Brighi; Hill, 2008, p. 123, tradução nossa, grifo dos autores).

Na mesma linha de Brighi e Hill (2008), Hudson (2014), atenta que a principal contribuição da APE é poder identificar onde esses fatores materiais (high politics) e ideacionais (low politics) se encontram em relação ao comportamento do Estado. Na ditadura, tais fatores são encontrados quando a Junta Militar foi confrontada diretamente pelos EUA a partir da política externa de Jimmy Carter, a qual condicionava transferências econômicas e militares conforme o quadro de direitos humanos dos países. Ou seja, a implementação da ação da Junta Militar em aceitar a CIDH e os possíveis resultados de sua visita respondiam a pressões não somente da agenda de direitos humanos, mas também de sanções de seus maiores parceiros, os EUA.

Isso demonstra que fatores materiais e ideacionais da política internacional no contexto da ditadura - direitos humanos, transferências econômicas, compra e venda de equipamento bélico - são, ao menos, "[...] moderadamente interligados, em parte porque qualquer política externa tem efeitos em distintos níveis, e também porque as camadas se sobrepõem de maneiras relevantes, empiricamente e conceitualmente" (Brighi; Hill, 2008, p. 123, tradução nossa). A política externa de Jimmy Carter encaixase nesse aspecto, visto que temáticas como segurança e economia poderiam passar para um segundo plano em relação à prioridade dos direitos humanos na diplomacia estadunidense (Novaro; Avenburg, 2009; Schmidli, 2013).

De acordo com Sikkink (1993), embora a Junta Militar tenha conseguido recuperar certa relevância internacional e acordos importantes, a conjunção da pressão moral e material causou transformações domésticas inescapáveis no quadro de direitos humanos na Argentina. Não obstante, tais pressões materiais são limitadas por nem sempre serem capazes de modificar a posição diplomática dos Estados. Na ditadura, a maleabilidade com que os militares tratavam o tema de direitos humanos ao proporcionar informações ocorreu mais porque a Argentina integrava um conjunto de países que

[...] aspiravam fazer parte da comunidade das nações enquanto uma comunidade normativa. As pressões são, geralmente, mais eficazes quando os Estados internalizaram as normas do regime de direitos humanos e resistem serem caracterizados como párias. [...] Não podemos entender por 
que os países, organizações e indivíduos preocupam-se com os direitos humanos ou por que os países respondem a pressões de direitos humanos sem considerar o papel das normas e ideias na vida internacional (Sikkink, 1993, p. 437-438, tradução nossa).

As tentativas da ditadura de colocar a população argentina contra a visita da CIDH e das ações dos opositores fizeram parte das estratégias da Junta Militar de implementar sua política externa de autêntica defensora dos direitos humanos frente à comunidade internacional. A propaganda "Os argentinos somos direitos e humanos" é uma amostra de como a fase de implementação deve considerar outros atores (nesse caso, grupos dissidentes da ditadura) enquanto variáveis da política externa. Esses atores, ao almejarem participar do processo de implementação, podem não apenas impulsionar ou facilitar a concretude dos objetivos propostos, mas "[...] criar fricção, aumentar os custos ou ao menos dificultar a implementação da política" (Brighi; Hill, 2008, p. 128, tradução nossa). A propaganda da ditadura voltava-se ao ambiente doméstico para angariar apoio da população, também impulsionada por sua política externa nacionalista e conservadora para assegurar legitimidade internacional. Com frequência, líderes de regimes autoritários "[...] usam apelos e discursos patrióticos para mobilizar apoio a seus assuntos de política externa" (Alden; Aran, 2017, p. 77, tradução nossa).

A visita da $\mathrm{CIDH}$ e as sanções dos EUA são amostras importantes de como ações consideradas pela ditadura como hostis podem ser transformadas em afrontas contra a soberania e a identidade de um país num contexto em que líderes buscam apoio doméstico e internacional (Alden; Aran, 2017). Na esteira de recuperar o apoio da sociedade argentina e colocá-la contra seus próprios cidadãos, os esforços da Junta Militar de obter sucesso na política externa necessitavam "[...] mobilizar apoio, neutralizar hostilidades, moldar o equilíbrio da influência e (gradualmente) ganhar as guerras de discursos que caracterizam o moderno e multinível sistema internacional" (Brighi; Hill, 2008, p. 129, tradução nossa).

Em abril de 1980, a ditadura publicou seu próprio informe que rechaçava as afirmações e considerações da CIDH. A ditadura negou todas as acusações de violações de direitos humanos: os chamados "excessos" da CIDH resultavam de uma situação excepcional que o país havia passado; tampouco os desaparecidos constituíam um problema pois não existiam para os militares, eram mortos em enfrentamentos 
armados, terroristas assassinados por suas próprias organizações, subversivos que estavam no exílio ou terroristas que tinham fugido do país para realizar campanhas antiArgentina (Jensen, 2010; Lloret, 2016; Novaro; Avenburg, 2009).

A Junta Militar distribuiu seu "contrainforme" para representações diplomáticas e governamentais, círculos políticos, serviços inteligência, imprensa, setores empresariais e aos militares dos EUA. Em resposta à CIDH, a Junta Militar declarou que o documento da Comissão era subjetivo e precipitado, além de ter se intrometido em assuntos domésticos e usado metodologias que distorciam a realidade na Argentina. Segundo a Junta Militar, conforme Ata 129 de 26 de fevereiro de 1980, o informe:

[...] ignora a realidade argentina da última década, que sem o conhecimento acabado é impossível compreender a situação atual e do passado recente. 0 informe não se ocupa da agressão terrorista, cuja magnitude e consequências explicam e justificam as medidas que o Governo teve de tomar para a defesa da sociedade, que nunca excederam a uma razoável resposta a essa tremenda agressão de que se era objeto (Argentina, 2014, p. 58, tradução nossa).

A ditadura, ao desqualificar o informe da $\mathrm{CIDH}$, movia-se para que o documento não fosse aprovado na Assembleia Geral da OEA. Na OEA, Raúl Alberto Quijano, Embaixador argentino na organização, sob ordens da Junta Militar, realizou uma campanha diplomática para angariar apoio dos países da organização contra o documento da $\mathrm{CIDH}$. O informe chegou à Assembleia Geral em 27 de novembro de 1980 que, ao final, não condenou a Argentina (Lisińska, 2019; Novaro; Avenburg, 2009).

Embora não condenada, a publicação do contrainforme da ditadura resultou na própria disseminação do informe da $\mathrm{CIDH}$, o que contribuiu ao debate público das justificativas da Junta Militar sobre os sequestros, as detenções e os desaparecimentos (Novaro; Avenburg, 2009). A chamada guerra contra a subversão passava a ser uma guerra suja contra a população argentina, os estrangeiros no país e os exilados:

[...] a visita do CIDH havia produzido uma fissura na barragem que mantinha protegida a opinião pública nacional do que se informava, suspeitava e debatia sobre a repressão ilegal na Argentina; e, por essa fissura, começou a se infiltrar uma incansável pressão dos familiares e críticas dos atores nacionais que tinham algo a demandar ao governo, inclusive daqueles que eram parte do regime, mas que por distintos motivos discordavam de Videla (Novaro; Avenburg, 2009, p. 84, tradução nossa).

Ao final, a visita da Comissão demonstrou que ambas as partes - os militares e seus opositores - estavam preocupados em (re)construir a história da ditadura (D'Antonio, 
2017; Jensen, 2010). Contudo, não foi possível silenciar as inúmeras violências cometidas pelos militares diante dos argentinos e da comunidade internacional.

\section{CONCLUSÃO}

A visita da $\mathrm{CIDH}$ em 1979 na Argentina foi um marco no campo dos direitos humanos do país. O evento potencializou o alcance e a visibilidade das denúncias realizadas pela oposição à ditadura, seja de grupos e indivíduos localizados na Argentina ou no exterior. A presença de um órgão internacional na Argentina, em plena ditadura, materializou elementos políticos, simbólicos e imagéticos da $\mathrm{CIDH}$ nas Américas enquanto mecanismo multilateral de direitos humanos responsável por apurar e contestar Estados responsáveis por graves violações de direitos humanos.

Embora a Junta Militar tenha feito uso político da soberania estatal para se blindar das acusações contra as denúncias ao categorizá-las como ingerência externa, afronta à nação e à identidade argentinas como autêntica defensora dos direitos humanos, o discurso de direitos humanos dos militares mudou no processo de negociação da visita. Se nos primeiros anos prevalecia uma retórica negacionista, em 1979 a Junta Militar adotou uma postura menos rígida que justificava as violações: deixava de negá-las para afirmar que eram resultado de confrontos entre os chamados pela ditadura de subversivos e desertores da pátria argentina.

Antes, durante e após a visita da $\mathrm{CIDH}$, a política externa da ditadura passou por diversas etapas: tentativa dos militares de deter ações domésticas e internacionais de denúncia, de silenciar a publicidade que a imprensa nacional dava à $\mathrm{CIDH}$ e de aumentar o clima nacionalista para colocar a sociedade contra a visita. Na construção e implementação das ações diplomáticas para a visita, o dissenso entre os militares frustrou a tentativa da Junta Militar de não ser considerada responsável pelas atrocidades e de consolidar uma boa imagem de seu governo.

Nessa perspectiva, os constrangimentos de atores domésticos e internacionais atuaram como forças de contenção da política externa da Junta Militar, que não soube administrar os distintos interesses e dificuldades diante de atores e contextos domésticos e internacionais. O contrainforme da ditadura em represália às observações da CIDH também demonstrou como a Junta Militar se preocupava com consequências 
materiais e imateriais sobre seu governo, as quais constituíram pressões que transformaram o quadro doméstico de direitos humanos da Argentina.

Os processos de tomada de decisão da política externa não foram lineares: a ditadura não era a única interessada em demonstrar à população ou à comunidade internacional a realidade na Argentina; grupos de direitos humanos, exilados, ONGs e Ols também disputaram esse objetivo. Se antes a Junta Militar se recusava a receber a $\mathrm{CIDH}$, e quando essa estava na Argentina salientou que o país não precisava dela (pois os argentinos eram direitos e humanos), ao final reuniu seus esforços para demonstrar, num movimento fracassado, que a Argentina era autêntica defensora dos direitos humanos. Contudo, já não era mais possível se blindar das inegáveis e indefensáveis atrocidades que o mundo passava a conhecer.

\section{REFERÊNCIAS BIBLIOGRÁFICAS}

Alden, C.; Aran, A. (2017). Foreign policy analysis: new approaches. New York: Routledge.

Argentina. (2014). Ministerio de Defensa. Actas de la Dictadura: documentos de la Junta Militar encontrados en el Edificio Cóndor. Tomo 3: actas 66 a 123, 11 de julio de 1978 11 de diciembre de 1979. Buenos Aires: Ministerio de Defensa. Disponível em: https://www.argentina.gob.ar/sites/default/files/actas tomo3.pdf. [Acesso em: 12 out. 2020].

Baehr, P. R.; Castermans-Holleman, M. (2004). The role of human rights in foreign policy. New York: Palgrave Macmillan.

Brighi, E.; Hill, C. (2008). 'Implementation \& behavior', In: Smith, S.; Hadfield, A. Foreign policy: theories, actors, cases. Oxford: Oxford Univ. Press, p. 117-136.

Calveiro, P. (2006). Poder y desaparición: los campos de concentración en Argentina. Buenos Aires: Colihue.

Carlsnaes, W. (2013). 'Foreign Policy', In: Carlsnaes, W.; Risse, T.; Simmons, B. A. (Ed.). Handbook of International Relations. London: Sage Publications, cap. 12. p. 298-325.

Comisión Provicinal Por La Memoria (CPM). (2020). La vigilancia de la comunidad informativa sobre la visita de la $\mathrm{CIDH}$ a la Argentina: Informe Especial. Disponível em: 
https://www.comisionporlamemoria.org/project/a-40-anos-de-la-visita-de-la-cidh-a-laargentina/. [Acesso em: 29 dez. 2020].

D'Antonio, D. (2017). 'Vigilancia, control social y agencia política del activismo por los derechos humanos ante la llegada de la Comisión Interamericana de Derechos Humanos (Argentina, 1979)', Izquierdas (Santiago), Santiago, n. 32, p. 184-202. Disponível em: $\quad$ https://scielo.conicyt.cl/scielo.php?script=sci arttext\&pid=S071850492017000100184\&lng=es\&nrm=iso. [Acesso em: 12 out. 2020].

Engstrom, P. (2016). 'The Inter-American Human Rights System and US-Latin American Relations', In: Scarfi, J. P.; Tillman, A. R. (Ed.). Cooperation and Hegemony in US-Latin American Relations: Revisiting the Western Hemisphere Idea. London: Palgrave Macmillan, cap. 6., p. 209-247.

Franco, M. (2008). El exilio: argentinos en Francia durante la dictadura. Buenos Aires: Siglo Veintiuno Editores.

Hill, C. (2003). The Changing Politics of Foreign Policy. NY: Palgrave Macmillan.

Hudson, V. M. (2014). Foreign policy analysis: classic and contemporary theory. Maryland: Rowman \& Littlefield.

Inter-American Commission on Human Rights (IACHR). (1978a). Annual Report. 43rd session (special). Disponível em: http://www.cidh.org/annualrep/78eng/toc.htm. [Acesso em: 8 out. 2019].

(1978b). Annual Report. 44th session. Disponível em: http://www.cidh.org/annualrep/78eng/toc.htm. [Acesso em: 29 dez. 2020.]

(1978c). Annual Report. 45th session. Disponível em: http://www.cidh.org/annualrep/78eng/toc.htm. [Acesso em: 29 dez. 2020]. (1979a). Annual Report. On-site Observation in the Republic of Argentina: 46th session. Disponível em: http://www.cidh.org/annualrep/7g.8oeng/toc.htm. [Acesso em: 29 dez. 2020.]

(1979b). Annual Report. Statute of the Inter-American Court of Human Rights: 48th session. Disponível em: http://www.cidh.org/annualrep/79.80eng/toc.htm. [Acesso em: 29 dez. 2020]. 
(1980). Annual Report. 52nd session. Disponível em: http://www.cidh.org/annualrep/80.81eng/TOC.htm. [Acesso em: 29 dez. 2020]. (1981). Annual Report: General Situation of Human Rights in the Member States of the OAS and areas in which further steps are needed to give effect to the Human Rights set forth in the American Declaration of the Rights and Duties of Man and The American Convention On Human Rights. 10th regular session. Disponível em: http://www.cidh.org/annualrep/80.81eng/TOC.htm. [Acesso em: 29 dez. 2020].

(1982a). Annual Report. 55th session. Disponível em: http://www.cidh.org/annualrep/81.82sp/indice.htm. [Acesso em: 29 dez. 2020].

(1982b). Annual Report. 56th session. Disponivel em: http://www.cidh.org/annualrep/81.82sp/indice.htm. [Acesso em: 29 dez. 2020]. (1982c). Annual Report. Twelfth Regular Session of the General Assembly of the Organization of American States. 12th regular session. Disponível em: http://www.cidh.org/annualrep/80.81eng/TOC.htm. [Acesso em: 29 dez. 2020]. Jensen, S. (2010). Los exiliados: la lucha por los derechos humanos durante la dictadura militar. Buenos Aires: Sudamericana.

Lisińska, M. (2019). Argentine Foreign Policy during the Military Dictatorship, 19761983: Between a Nationalist \& Pragmatic Approach. Cham: Palgrave Macmillan.

Lloret, R. (2016). 'Represión, derechos humanos y política exterior: El rol de los diplomáticos argentinos en el Comité de Derechos Humanos de la ONU (1976-1983)', Papeles de Trabajo, v. 10, n. 17, p. 126-146. Disponível em: https://dialnet.unirioja.es/servlet/articulo?codigo=5875341. [Acesso em: 12 out. 2020]. McSherry, J. P. (2005). Predatory states: Operation Condor and covert war in Latin America. Lanham. MD: Rowman \& Littlefield Publishers.

Míguez, M. C.; Morgenfeld, L. (2017). 'Política exterior y movimiento social: análisis de grandes manifestaciones frente a destacados visitantes extranjeros en la Argentina (1963-1983)', Trabajos y Comunicaciones, v. 1, n. 45, p. 1-25. UNLP. Disponível em: https://dialnet.unirioja.es/servlet/articulo?codigo=5913767. [Acesso em: 12 out. 2020]. Mintz, A.; DeRouen Jr., K. (2010). Understanding Foreign Policy Decision Making. Cambridge: Cambridge University Press. 
Novaro, M.; Avenburg, A. (2009). 'La CIDH En Argentina: Entre La Democratización y Los Derechos Humanos', Desarrollo Económico, v. 49, n. 193, p. 61-90. Disponível em: www.jstor.org/stable/20627863. [Acesso em: 29 dez. 2020].

Novaro, M.; Palermo, V. (2007). A ditadura militar argentina, 1976-1983: do golpe de Estado à restauração democrática. São Paulo: EDUSP.

Quiroga, H. (2004). El tiempo del "Proceso". Conflictos y coincidencias entre políticos y militares 1976-1983. 2. Ed. Santa Fe: Horno Sapiens: Fundación Ross.

Roniger, L. (2018). Historia mínima de los derechos humanos en América Latina. Ciudad de México: El Colegio de México.

Salomón, M.; Pinheiro, L. (2013). 'Análise de Política Externa e Política Externa Brasileira: trajetória, desafios e possibilidades de um campo de estudos', Rev. bras. polít. int., Brasília, v. 56, n. 1, p. 40-59. Disponível em: http://www.scielo.br/scielo.php?script=sci arttext\&pid=S003473292013000100003\&lng=en\&nrm=iso. [Acesso em: 29 dez. 2020].

Schmidli, W. M. (2013). The fate of freedom elsewhere: human rights and U.S. Cold War policy toward Argentina. Ithaca, N.Y.: Cornell Univeristy Press.

Sikkink, K. (1993). 'Human Rights, Principled Issue-Networks, and Sovereignty in Latin America', International Organization, v. 47, n. 3, p. 411-441. Disponível em: http://www.jstor.org/stable/2706982. [Acesso em: 28 jan. 2019]. . (2018). Razones para la esperanza: la legitimidad y efectividad de los derechos humanos de cara al futuro. Buenos Aires: Siglo Veintiuno Editores. 